\title{
Twenty Years of Experience of Fracture Neck of Femur in Pediatric Population in Southern China
}

\author{
Clara On-Ki Lee ${ }^{1}$, Wai-Wang Chau ${ }^{2}$, Victor Illescas ${ }^{3}$, Bobby Kin-Wah Ng ${ }^{4}$
}

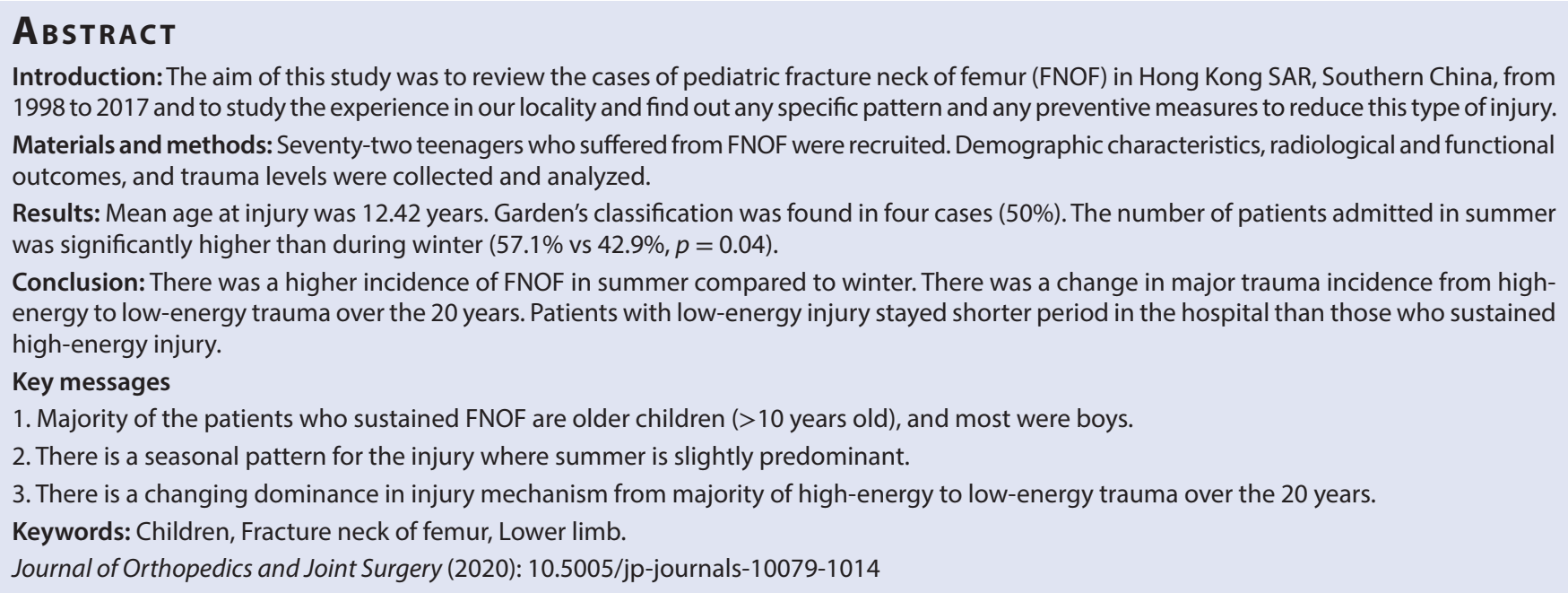

\section{INTRODUCTION}

Fracture neck of femur (FNOF) is a rare injury in pediatric population, which accounts for less than $1 \%$ of all pediatric fractures. ${ }^{1,2}$ However, it is associated with various significant complications due to the vulnerable vascular supply to proximal femur in children. ${ }^{2-5}$ Complications include malunion, nonunion, coxa vara, and avascular necrosis of femoral head being the most serious and worrisome complication. ${ }^{2-10}$ It significantly affects the functional outcome in this young population.

This study attributed the low incidence of fracture neck of femur in pediatric population to the different anatomy in this age-group. ${ }^{11,12}$ Children have higher bone density with thicker and stronger periosteum. ${ }^{10}$ Most of them suffered from fracture neck of femur, hence had sustained high-energy trauma such as road-traffic accident or fall from height, and were more likely to be associated with other soft tissue or bone injuries. ${ }^{5,13}$ However, it is observed in our daily hospital setting that low-impact trauma has become more commonly seen in recent years. Compared to 1990 s that most patients with fracture neck of femur usually sustained high-energy trauma ${ }^{14}$ there is a changing trend that patients suffered from this fracture after slipped and fallen. Therefore, we would like to analyze the changing trend on injury mechanism for fracture neck of femur.

A review article on the management of pediatric femoral neck fracture in 2018 acknowledged that fractures at femoral head were rare, but the long-term sequelae with potential disabling were a very important issue for sufferers. ${ }^{15}$ Delbet's classification was the commonest classification system on prognosis and providing treatment guidelines. Treatments were mainly achieving union at fracture site to avoid osteonecrosis. Risk factors have yet to be explored. A European study retrospectively reviewing high- and
${ }^{1-4}$ Department of Orthopaedics and Traumatology, Chinese University of Hong Kong, Hong Kong

Corresponding Author: Clara On-Ki Lee, Department of Orthopaedics and Traumatology, Chinese University of Hong Kong, Hong Kong, Phone: +(852) 6647-6409, e-mail: leeonki_clara@yahoo.com.hk

How to cite this article: Lee C, Chau WW, Illescas V, et al. Twenty Years of Experience of Fracture Neck of Femur in Pediatric Population in Southern China. J Orth Joint Surg 2020;2(1):26-30.

Source of support: Nil

Conflict of interest: None

low-trauma fracture patterns between 2010 and 2012 summarized that high-trauma fracture increased the risk of future low-trauma non-vertebral fractures; however, the subjects recruited in this study were postmenopausal women and similarly aged men at an age range of 54-70 years, leaving similar research particularly concerning pediatric patients a very important topic. ${ }^{16}$ The results from another retrospective analysis on mechanism of injury, associated injuries, procedures, and subsequent follow-up on pediatric patients with femoral shaft fractures over a 10 -year period showed that $58 \%$ of pediatric femur fractures were caused by low-energy trauma. ${ }^{17}$ An early retrospective study in 1999 reported 14 cases of fracture neck of femur in patients under 16 years old in Hong Kong over a 10 -year period. ${ }^{14}$ Since then, there is inadequate statistics on this type of injury in our locality. The study showed that age of injury, fracture type, and degree of displacement are significant factors predicting the development of avascular necrosis..$^{3-5,9,18-20}$ Fracture patterns that displace more had worse outcome than those with less displacement. ${ }^{21}$ Studying on the experience may help us have 
more understanding on this injury, identify any specific pattern of it, and provide statistic evidence on any predictive factor on the outcome after having fracture neck of femur.

The aim of this study was to review the cases of pediatric FNOF in Hong Kong SAR, Southern China, from 1998 to 2017 and to study the experience in our locality. This study aims to find out any specific pattern and any preventive measures to reduce this type of injury.

\section{Materials and Methods}

This is a retrospective cohort study carried out in a local hospital in Hong Kong SAR, Southern China. Hospital admission records were searched retrospectively using CDMARS system for the list of patients admitted to pediatric ward. Ethical approval was obtained from the local ethics review board (ethics approval number: 2018.329). All patients were aged under 18 years and fractured and operated on between 1986 and 2016, and those who suffered from FNOF were included. The treatment methods included fixation in situ, closed reduction internal fixation with decompression by aspiration or X-rays-guided scissor capsulotomy and open reduction internal fixation. Fractured patients after surgery were followed up with X-rays and MRI at 6 weeks, 6 and 12 months for the assessment of AVN. Exclusion criteria included pathological fractures such as osteogenesis imperfecta, cerebral palsy, and other congenital disorders.

In each patient record, age of injury, sex, and injury mechanism were retrieved. Injury mechanism is classified as low-energy injury and high-energy injury. Low-energy injury is, by definition, that no trauma or minimal trauma occurred, such as fall from ground level. Fall from height ( $>3 \mathrm{~m}$ ) and motorized vehicle injuries were defined as high-energy injury. Furthermore, date of admission and date of discharge, fracture pattern including side of fracture, seasonal pattern, Garden's classification, and Delbet's classification were reviewed.

"Winter" referred to December to April, and May to November was defined as "Summer." Outcomes including functional outcomes and radiological outcomes after suffering the injury were also reviewed. Data analysis was performed using IBM SPSS 25.0 (Armonk, New York). A two-sided $p$ value $\leq 0.05$ was considered statistically significant.

\section{Results}

Eighty patients who suffered from FNOF from 1998 to 2017 were recruited in this study. Eight patients were excluded owing to pathological fracture or other congenital disorders, making the final number of patients to be 72 . Baseline demographic characteristics, surgical details, radiographic and functional outcomes, and comparisons between patients who suffered from low-energy and high-energy trauma were analyzed for all 72 patients. Further analysis followed by stratifying the database into two groups, by the year of admission: (1) year 1998-2007 and (2) year 2008-2017. The reason for dividing the database was that we spotted an obvious change in the injury mechanism from high-energy trauma to lowenergy trauma starting from the year 2008. There were 40 and 32 patients who suffered from FNOF between 1998 and 2007, and between 2008 and 2017, respectively.

Overall mean age at injury was 12.42 years, of which 8 (11.1\%) were under 10 years old and 64 (88.9\%) were above 10 years old (Table 1). Mean age at injury from 1998-2007 and 2008-2017 was
Table 1: Demographic characteristics of the 72 patients

\begin{tabular}{|c|c|}
\hline Demographic variables & $n(\%)$ \\
\hline \multicolumn{2}{|l|}{ Sex } \\
\hline Male & $49(68.1)$ \\
\hline Female & $23(31.9)$ \\
\hline \multicolumn{2}{|l|}{ Side } \\
\hline Left & $7(77.8)$ \\
\hline Right & $2(22.2)$ \\
\hline Unknown & 63 \\
\hline \multicolumn{2}{|l|}{ Year of admission } \\
\hline 1998-2007 & $40(55.6)$ \\
\hline 2008-2017 & $32(44.4)$ \\
\hline \multicolumn{2}{|l|}{ Injury mechanism } \\
\hline Fall from height & $11(15.3)$ \\
\hline Fall on ground level & $41(56.9)$ \\
\hline Fall, NOS & $4(5.6)$ \\
\hline Others & $5(6.9)$ \\
\hline Road-traffic accident & $8(11.1)$ \\
\hline \multicolumn{2}{|l|}{ Fracture pattern (garden) } \\
\hline I & $4(50.0)$ \\
\hline$\|$ & $2(25.0)$ \\
\hline IV & $2(25.0)$ \\
\hline Unknown & 64 \\
\hline \multicolumn{2}{|l|}{ Fracture pattern (Pauwels) } \\
\hline II & $1(50.0)$ \\
\hline III & $1(50.0)$ \\
\hline Unknown & 70 \\
\hline
\end{tabular}

NOS, not otherwise specific

both 12.4 years old (1998-2007: $12.40 \pm 2.76,2008-2017$ : $12.44 \pm$ 2.88). 49 cases (68.1\%) were male, and 23 cases (31.9\%) were female.

Ten cases (13.9\%) had associated injury; orthopedics-related injuries include fracture humerus shaft (1 case), fracture ulnar shaft (1 case), fracture olecranon (1 case), posterior dislocation of elbow (1 case), fracture cuboid (1 case), femoral shaft fracture (2 cases), fracture tibial shaft (1 case), bimalleolar fracture (1 case), and fracture calcaneus (1 case). Other non-orthopedics-related injuries include open wound of scalp ( 2 cases), pneumothorax (1 case), lung contusion (1 case), kidney laceration (1 case), and concussion with deep coma (1 case).

Nine patients were discharged from the hospital after surgery, and detailed data on CMS were reviewed. Seven of them (77.8\%) had fracture left NOF, and 2 of them (22.2\%) had fracture right NOF. According to Garden's classification, four cases (50\%) had type I fracture, two cases (25\%) had type II fracture, two cases (25\%) had type IV fracture, and the remaining one case had no available radiological film for review. According to Delbet's classification, 1 case (2\%) had type I fracture, 41 cases (61\%) had type II fracture, 10 cases (15\%) had type III fracture, 7 cases (10\%) had type IV fracture, and the remaining patients had no available radiological film for review.

As for the injury mechanism, it was classified into low-energy injury and high-energy injury as defined (Table 2). In 1998-2007, 21 (60\%) patients sustained low-energy injury, while $14(40 \%)$ had high-energy trauma ( $p<0.01)$. In 2008-2017, 24 (82.8\%) patients 
Twenty Years of Experience of Fracture Neck of Femur in Children

Table 2: Classification of injury mechanism (low- and high-energy trauma) by causes of fractures under the two periods

\begin{tabular}{|c|c|c|c|c|c|c|}
\hline \multirow[b]{2}{*}{ Causes of fractures } & \multicolumn{3}{|c|}{ 1998-2007 } & \multicolumn{3}{|c|}{ 2008-2017 } \\
\hline & Low energy & High energy & $p$ value & Low energy & High energy & $p$ value \\
\hline Fall from height & 0 & $8(57.1)$ & $<0.01$ & 0 & $3(60.0)$ & $<0.01$ \\
\hline Fall on ground level & $18(85.7)$ & 0 & & $23(95.8)$ & 0 & \\
\hline $\begin{array}{l}\text { Fall on ground level, } \\
\text { suspected }\end{array}$ & $3(14.3)$ & 0 & & $1(4.2)$ & 0 & \\
\hline RTA & 0 & $6(42.9)$ & & 0 & $2(40.0)$ & \\
\hline
\end{tabular}

RTA, road-traffic accident

Table 3: Comparisons of surgical details, treatment outcomes, and periods between important dates between patients suffered from low- or high-energy trauma in the two periods

\begin{tabular}{|c|c|c|c|c|c|c|}
\hline \multirow[b]{2}{*}{ Variables } & \multicolumn{3}{|c|}{ 1998-2007 } & \multicolumn{3}{|c|}{$2008-2017$} \\
\hline & Low energy & High energy & $p$ value & Low energy & High energy & pvalue \\
\hline $\begin{array}{l}\text { Operation duration } \\
\text { (minute) }\end{array}$ & $56.67 \pm 10.41$ & - & - & $46.67 \pm 12.58$ & $81.50 \pm 79.90$ & 0.001 \\
\hline Blood aspirated (mL) & $9.00 \pm 1.41$ & - & - & $99.00 \pm 0.00$ & $12.50 \pm 10.61$ & 0.534 \\
\hline Length of stay (days) & $15.57 \pm 12.70$ & $24.79 \pm 33.28$ & 0.336 & $8.76 \pm 6.02$ & $25.71 \pm 20.70$ & 0.648 \\
\hline $\begin{array}{l}\text { Days between OT and } \\
\text { admission }\end{array}$ & $12.35 \pm 8.85$ & $16.46 \pm 7.91$ & 0.184 & $22.32 \pm 45.65$ & $11.29 \pm 8.56$ & 0.001 \\
\hline $\begin{array}{l}\text { Days between hospital } \\
\text { discharge and OT }\end{array}$ & $8.00 \pm 4.58$ & - & - & $18.00 \pm 9.90$ & $17.00 \pm 0.00$ & 0.948 \\
\hline $\begin{array}{l}\text { Days between hospital } \\
\text { discharge and admission }\end{array}$ & $9.00 \pm 5.66$ & - & - & $136.50 \pm 157.68$ & $17.00 \pm 0.00$ & 0.647 \\
\hline $\begin{array}{l}\text { Days between latest } \\
\text { follow-up and discharge }\end{array}$ & $1441.00 \pm 1192.31$ & - & - & $2047.67 \pm 1042.49$ & $1188.50 \pm 28.99$ & 0.350 \\
\hline
\end{tabular}

OT, operation

sustained low-energy injury, while 5 (17.2\%) sustained high-energy trauma $(p<0.01)$.

Length of hospital stay and radiological outcomes in patients undergoing low-energy and high-energy trauma were assessed. In 1998-2007, the mean length of stay for those with low-energy injury was 15.57 days, while the length of stay for those with high-energy injury was 24.79 ( $p=0.336$ ) (Table 3). In 2008-2017, the mean length of stay for those with low-energy injury was 8.76 days, while the length of stay for those with high-energy injury was 25.71 ( $p=0.648)$.

Radiological outcome between low-energy trauma and highenergy trauma patients was compared. No evidence of avascular necrosis on X-ray and MRI was observed (Table 4). In 2009-2017, one case who suffered from low-energy injury had mild collapse of femoral head on X-ray, two had evidence of avascular necrosis of left hip on $\mathrm{MRI}$, and one had evidence of avascular necrosis of right hip on MRI.

Forty cases (57.1\%) were admitted during summer time (MayNovember), and 30 cases (42.9\%) were admitted during winter time (December-April) (Table 5). Over the study period, percentages of bone fractures caused by road-traffic accident were reported in summer only (summer vs winter: $21.1 \%$ vs $0 \%$ ). On the other side, in winter, the fracture percentage caused by falling from height was much higher than in summer $(28.0 \%$ vs $10.5 \%)$ (overall $p=$ 0.04) (Table 6).

\section{Discussion}

Majority of the patients who sustained FNOF were older children or teenagers ( $>10$ years old), and most of them were boys. Older patients tended to be more commonly suffered from this injury, which could be due to the difference in anatomy in children.11,12 They have higher bone density with thicker and stronger periosteum.

Predominant type of FNOF observed was type I according to Garden's classification, which is incomplete fracture with minimal displacement. According to Delbet's classification, most of the patients had type II fracture, which is transcervical fracture.

There was a higher incidence of FNOF in summer time compared to winter time. This could be related to the activity level of children. It was believed that the incidence of pediatrics fracture is higher in summer time because of the summer vacation and unsupervised physical activity. ${ }^{22}$ However, one recent study showed that there may be a changing pattern in seasonal variation of pediatrics fracture. ${ }^{23}$ It showed a bimodal pattern with similar nadirs in summer time and winter time, with possible reasons of sedentary lifestyle in children nowadays. To draw conclusion on the incidence of pediatric FNOF and seasonal variation in our locality, we may need further details for analysis.

There is a changing dominance in injury mechanism over the 20 years where there was increasing proportion of patients who suffered from low-energy trauma. In 1998-2007, 60\% of them sustained low-energy injury, while $40 \%$ had high-energy trauma. In 2008-2017, majority of them sustained low-energy injury (82.8\%), while only $17.2 \%$ sustained high-energy trauma. Our observations were similar to those of Caldwell et al., of which $58 \%$ of pediatric femur fractures were low-energy trauma. ${ }^{17}$ One of the underlying causes of the changing dominance could be the change in patients' bone mineral density across the 20 years. Two patients with FNOF secondary to trip and fall had low bone density on DEXA score. One was -1.71 , while the other was -2.16 at L2-L4 and -2.55 at femur. It 
Table 4: Comparisons of X-ray findings, MRI findings, and revision surgery required between patients who suffered from low- or high-energy trauma in the two periods

\begin{tabular}{|c|c|c|c|c|c|c|}
\hline & \multicolumn{3}{|c|}{ 1998-2007 } & \multicolumn{3}{|c|}{ 2008-2017 } \\
\hline & Low energy & High energy & $p$ value & Low energy & High energy & $p$ value \\
\hline \multicolumn{7}{|l|}{ X-ray } \\
\hline No sign of AVN & $3(13.0)$ & 0 & 0.275 & $2(8.0)$ & $2(28.6)$ & 0.315 \\
\hline $\begin{array}{l}\text { Mild collapse of femoral } \\
\text { head }\end{array}$ & 0 & 0 & & $1(4.0)$ & 0 & \\
\hline Unknown & $20(87.0)$ & $14(100.0)$ & & $22(88.0)$ & $5(71.4)$ & \\
\hline \multicolumn{7}{|l|}{ MRI } \\
\hline AVN of left hip & 0 & 0 & 0.275 & $2(13.5)$ & 0 & 0.086 \\
\hline AVN of right hip & 0 & 0 & & $1(3.70)$ & 0 & \\
\hline No evidence of AVN & $3(13.0)$ & 0 & & 0 & $1(14.3)$ & \\
\hline Unknown & $20(87.0)$ & $14(100.0)$ & & $23(88.89)$ & $5(85.7)$ & \\
\hline \multicolumn{7}{|l|}{ Need of revision } \\
\hline $\begin{array}{l}\text { Early removal of screw } \\
\text { with core decompression }\end{array}$ & 0 & 0 & - & $1(4.0)$ & 0 & 0.264 \\
\hline Removal of screw & 0 & 0 & & 0 & $1(14.3)$ & \\
\hline $\begin{array}{l}\text { Screw to right proximal } \\
\text { femur (change of screw) }\end{array}$ & 0 & 0 & & $1(4.0)$ & 0 & \\
\hline Unknown & $23(100.0)$ & $14(100.0)$ & & $23(92.0)$ & $685.7)$ & \\
\hline
\end{tabular}

AVN, avascular necrosis

Table 5: Reported fracture cases between 1998 and 2017

\begin{tabular}{lll}
\hline Month & Winter & Summer \\
\hline January & $5(16.7)$ & - \\
February & $5(16.7)$ & - \\
March & $5(16.7)$ & - \\
April & $8(26.7)$ & - \\
May & - & $4(10.0)$ \\
June & - & $4(10.0)$ \\
July & - & $6(15.0)$ \\
August & - & $7(17.5)$ \\
September & - & $6(15.0)$ \\
October & - & $5(12.5)$ \\
November & - & $8(20.0)$ \\
December & $7(23.3)$ & - \\
Total & 30 & 40 \\
\hline
\end{tabular}

was stated that osteoporosis in children is often underdiagnosed. A study reviewed that in children who sustained two or more fractures without serious trauma, most were osteoporotic or osteopenic in their hips or bones. ${ }^{22}$ The poor bone quality in children may cause them to sustain hip fracture without significant injury. One of the patients was also recorded to have a low BMI of 12.9, which is less than $5 \%$ and defined as underweight. This could also account for the low-energy injury causing FNOF. Further study could be done to establish the relationship between low bone density and low BMI with FNOF.

As for the outcome of FNOF, the length of stay in the hospital for those with low-energy injury was less than that for those who sustained high-energy injury. Also, patients who sustained lowenergy injury in 2008-2017 stayed for a shorter period of time in the hospital than those in 1998-2007. This could be caused by the advancement in surgery in recent years. Nowadays patients
Table 6: Reported and defined injury mechanisms happened in winter and summer

\begin{tabular}{lccl}
\hline & \multicolumn{2}{c}{ Season } & \\
\cline { 2 - 3 } Injury mechanism & Winter & Summer & p value \\
\hline Fall from height & $7(28.0)$ & $4(10.5)$ & 0.04 \\
Fall on ground level & $17(68.0)$ & $23(60.5)$ & \\
$\begin{array}{l}\text { Fall from unknown } \\
\text { height }\end{array}$ & $1(4.0)$ & $3(7.9)$ & \\
Road-traffic accident & 0 & $8(21.1)$ & \\
\hline
\end{tabular}

presented with FNOF are treated by closed reduction internal fixation of femur with needle capsulotomy. Advancement in surgery could promote the healing progress for the patient, leading to shorter length of hospitalization.

However, for the radiological outcomes, the impact of injury mechanism on avascular necrosis was inconclusive. Cases reported to have avascular necrosis were those with low-energy injury. It was believed that the rate of avascular necrosis is directly related to the initial degree of displacement. ${ }^{24}$ Early and accurate reduction and fixation also contributes to the prevention of this complication. When reviewing the details of data of our patients, there is no definite conclusion on factors affecting the risk of avascular necrosis and injury mechanism may not be associated with it. In a 12-year-old girl with low-energy injury and undisplaced fracture, closed reduction internal fixation with capsulotomy was done within 10 hours after admission. Follow-up imaging showed that she had type II avascular necrosis on MRI scan. In another 14-year-old girl who sustained high-energy injury with undisplaced fracture, closed reduction and hip screw with joint aspiration was done. She remains asymptomatic and developed no avascular necrosis postoperatively. It is observed that the complication can occur even in undisplaced fracture. Treatment method might be more determinant on the prevention of complication. 


\section{Limitations}

There are limited cases and data to further study the risk factors for avascular necrosis. A part of the hospital data were highly restricted and could not be accessed due to data security issues (e.g., side of fracture, fracture pattern, X-ray and MRI results on follow-up). Some of the data could not be retrieved or collected due to the retrospective nature of this study.

\section{Conclusion}

Majority of the patients who sustained FNOF are older children ( $>10$ years old), and most were boys. There is a seasonal pattern for the injury where the summer time is slightly predominant. There is a changing dominance in the injury mechanism from majority of high-energy to low-energy trauma over the 20 years. Factors influencing the increasing rate of low-energy trauma have yet to be explored.

\section{References}

1. Ratliff $A H$. Fractures of the neck of the femur in children. J Bone Joint Surg Br 1962;44(3):528-542. DOI: 10.1302/0301-620X.44B3.528.

2. Canale ST. Fractures of the hip in children and adolescents. Orthop Clin North America 1990;21(2):341-352.

3. Canale ST, Bourland WL. Fracture of the neck andintertrochanteric region of the femur in children. J Bone Joint Surg Am 1977;59(4): 431-443. DOI: 10.2106/00004623-197759040-00001.

4. Hughes LO, Beaty JH. Fractures of the head and neck of the femur in children. J Bone Joint Surg Am 1994;76(2):283-292. DOI: 10.2106/00004623-199402000-00019.

5. Kuo F-C, Kuo S-J, Ko J-Y, et al. Complications of hip fractures in children. Chang Gung Med J 2011;34(5):512-519.

6. Ratliff AHC. Complications after fractures of the femoral neck in children and their treatment. J Bone Joint Surg 1970;52-B:175.

7. Bagatur $A E$, Zorer $G$. Complications associated with surgically treated hip fractures in children. J Pediatr Orthop B 2002;11(3):219-228. DOI: 10.1097/01202412-200207000-00005.

8. Colonna PC. Fractures of the neck of the femur in children. Am J Surg 1929;6(6):793-797. DOI: 10.1016/S0002-9610(29)90726-1.

9. Forlin E, Guille JT, Kumar SJ, et al. Complications associated with fracture of the neck of femur in children. J Pediatr Orthop 1992;12(4):503-509. DOI: 10.1097/01241398-199207000-00017.

10. Kay SP, Hall JE. Fracture of the femoral in children and its complications. Clin Orthop 1971;80:53-71. DOI: 10.1097/00003086197110000-00009.
11. Quick TJ, Eastwood DM. Pediatric fractures and dislocations of the hip and pelvis. Clin Orthop Relat Res 2005;432(432):87-96. DOI: 10.1097/01.blo.0000155372.65446.40.

12. Kamal Bali MS, Pebam Sudesh MS, Sandeep Patel MS, et al. MS pediatric femoral neck fractures: our 10 years of experience. Clin Orthop Surg 2011;3:302-308.

13. Mirdad T. Fractures of the neck of the femur in children: an experience at the Aseer central hospital, Abha, Saudi Arabia. Injury 2002;33(9):823-827. DOI: 10.1016/s0020-1383(02)00013-x.

14. Cheng JC, Tang N. Decompression and stable internal fixation of femoral neck fractures in children can affect the outcome. J Pediatr Orthop 1999;19(3):338-343. DOI: 10.1097/01241398-19990500000010.

15. Patterson JT, Tangtiphaiboontana J, Pandya NK. Management of pediatric femoral neck fracture. J Am Acad Orthop Surg 2018;26(12):411-419. DOI: 10.5435/JAAOS-D-16-00362.

16. Muschitz C, Kocijan R, Baierl A, et al. Preceding and subsequent highand low-trauma fracture patterns-a 13-year epidemiological study in females and males in Austria. Osteoporos Int 2017;28(5):1609-1618. DOI: 10.1007/s00198-017-3925-3.

17. Caldwell L, Chan CM, Sanders JO, et al. Detection of femoral neck fractures in pediatric patients with femoral shaft fractures. J Pediatr Orthop 2017;37(3):e164-e167. DOI: 10.1097/BPO.0000000000000800.

18. Moon ES, Mehlman CT. Risk factors for avascular necrosis after femoral neck fractures in children: 25 cincinnati cases and Metaanalysis of 360 cases. J Orthop Trauma 2006;20(5):323-329. DOI: 10.1097/00005131-200605000-00005.

19. Pforringer $W$, Rosemeyer $B$. Fractures of the hip in children and adolescents. Acta Orthop Scand 1980;51(1-6):91-108. DOI 10.3109/17453678008990774.

20. Swiontkowski MF, Winquist RA. Displaced hip fractures in children and adolescents. J Trauma 1986;26(4):384-388. DOI: 10.1097/00005373198604000-00013.

21. Morsy HA. Complications of fracture of the neck in the femur in children: A long-term follow-up study. Injury 2001;32(1):45-51. DOI: 10.1016/s0020-1383(00)00109-1.

22. Landin LA. Fracture patterns in children. analysis of 8,682 fractures with special reference to incidence, etiology and secular changes in a swedish urban population 1950-1979. Acta Orthop Scand Suppl 1983;202:1-109.

23. Segal D, Slevin O, Aliev E, et al. Trends in the seasonal variation of paediatric fractures. J Child Orthop 2018;12(6):614-621. DOI: 10.1302/1863-2548.12.180114.

24. Key LL Jr, Ries W, Madyastha P, et al. Juvenile osteoporosis: recognizing the risk. J Pediatr Endocrinol Metab 2003;16(Suppl 3):683-686. 